\title{
Predictors of Quality of Life and Social Support as a Mediator between Defecation Function and Quality of Life among Rectal Cancer Patients
}

Kim, Jung Rang ${ }^{10}$. Hwang, Seon Young ${ }^{2}$

${ }^{1}$ Nurse, Colorectal Clinic, Asan Medical Center, Seoul, Korea

${ }^{2}$ Professor, School of Nursing, Hanyang University, Seoul, Korea

Purpose: To identify the factors influencing Quality of Life (QoL) in rectal cancer patients and to examine whether perceived social support mediates the relationship between defecation function and QoL. Methods: Using self-report questionnaires, a descriptive survey was conducted with 131 rectal cancer patients who underwent anal sphincter-saving resection, in a large medical center in Korea. Data were collected between September and November, 2014, using research instruments validated in the Korean language. The data were analyzed using SPSS/WIN 21.0 and AMOS 21.0. Results: The mean age and post-surgical follow-up period of the participants were $59.0 \pm 10.2$ years and $15.9 \pm 9.8$ months, respectively. Multiple linear regression analysis revealed that, after adjusting for age and gender, defecation function, perceived social support, and employment status predicted QoL. Path analysis showed that perceived social support partially mediated the relationship between defecation function and QoL with a significant indirect effect. Conclusion: These results suggest that a positive perception of social support from family and healthcare providers is necessary to improve the QoL of patients experiencing defecation dysfunction after rectal cancer surgery. To this end, periodic counseling and education from outpatient healthcare providers, during the postoperative follow-up period, could encourage patients to perceive higher social support.

Key Words: Rectal neoplasms; Defecation; Social support; Quality of life

\section{INTRODUCTION}

Colorectal cancer is the third most common cancer, accounting for $12.4 \%$ of all cancers in Korea. Approximately $45 \%$ of colorectal cancer cases arise in the rectum, accounting for $5.4 \%$ of all cancer cases. Rates of colorectal cancer are increasing faster than those of other cancer types with high prevalence rates [1]. The increased incidence of colorectal cancer in recent years has largely been attributed to a westernized diet, increased alcohol consumption, and decreased physical activity [2]. Recent advances in treatment technology have resulted in improved survival of patients with colorectal cancer, and their Quality of Life (QoL) is an increasingly important aspect of long-term care for chronic illness. Approximately $80 \%$ of patients with rectal cancer undergo sphincter-saving surgery; the ultimate goal of this surgical procedure is to minimize complications through radical resection, thereby preserving the anal sphincter muscle and improving QoL [3].

A systematic review reported that up to $60 \%$ of rectal cancer patients who underwent sphincter-saving resection reported urgency of defecation, frequent bowel movements, fecal incontinence, and changes in erectile function [4]. Defecation dysfunction is characterized by frequent passage of stools, feeling of defecation, urgency of defecation, loose feces, feeling of incomplete defecation, and constipation [5]. Particularly, patients with rectal cancer who undergo sphincter-saving resection persistently report defecation function problems as a long- term adverse effect over the course of four years after definitive treatment [6]. They are also often treated with a combination of radiation therapy and chemotherapy, which can cause symptoms of

Corresponding author: Hwang, Seon Young https://orcid.org/0000-0003-3613-3350

School of Nursing, Hanyang University, 222 Wangsimni-ro, Seongdong-gu, Seoul 04763, Korea.

Tel: +82-2-2220-0702, Fax: +82-2-2220-1163, E-mail: seon9772@hanyang.ac.kr

Received: May 23, 2019 / Revised: Jul 25, 2019 / Accepted: Aug 23, 2019

This is an open access article distributed under the terms of the Creative Commons Attribution Non-Commercial License (http://creativecommons.org/licenses/ by-nc/3.0), which permits unrestricted non-commercial use, distribution, and reproduction in any medium, provided the original work is properly cited. 
defecation dysfunction and negatively affect physical, psychological, and social functioning during the treatment period, in addition to a marked decline in QoL [6]. Furthermore, patients with rectal cancer are reported to have lower QoL than patients with gastric or colon cancer due to the presence of symptoms of defecation dysfunction [7].

Previous studies have found that anxiety/depression [8], younger age, lower economic status, and higher nutritional risk are factors affecting QoL in patients with surgically treated colorectal cancer [9]. In addition, social support from the family and from healthcare professionals was found to predict lower stress and greater QoL in colorectal cancer patients [10], whereas symptom distress, such as defecation problems, made patients more depressed, and lowered perceived social support, as well as=QoL [11]. Cohort studies report that colorectal cancer patients with high perceived social support and no psychological distress have better QoL one year after surgery [12], and about one-third of patients have decreasing levels of perceived social support two years after surgery, which is closely related to lower QoL [13]. Therefore, the support of healthcare professionals and the family seems to be very important for the patients, who need to follow up through outpatient clinic for a considerable period after surgery, and it is necessary to consider the role of social support in planning interventions for this population.

Perceived social support is likely to be higher if the patient feels that his or her needs are met by the healthcare professional or the family during the post-operative recovery period. However, a systematic review reported that colorectal cancer patients expressed diverse unmet needs after surgery, encompassing emotional support, information about diet and long-term self-management of symptoms, and complications at home [14]. They also experienced a lack of supportive care after discharge and wanted counseling received from healthcare professionals during the preoperative period to extend to the postoperative period, including instructions on the use of self-management skills for their functional complaints or symptoms [3, 15]. The information needs of patients can be met by providing social support in the form of counseling and education by nurses; such psychological interventions can help them overcome post-surgical symptoms and successfully cope with the disease, thereby improving their QoL [12].

To summarize, rectal cancer patients with defecation dysfunction are likely to be more satisfied if they receive social support from their families and health care professionals. In other words, perception of social support can be hypothesized to be an indirect variable to explain the relationship between defecation function and QoL in patients with rectal cancer during the follow-up period. Social support has been found to mediate between symptom distress and QoL in gastric cancer patients [16]. Therefore, the purpose of the present study is two-fold: (1) to identify factors predicting QoL and, (2) to investigate whether perceived social support mediates the relationship between defecation function and QoL, in patients with rectal cancer, after anal sphincter-saving surgery.

\section{METHODS}

\section{Study Design}

The study adopted a descriptive. correlational design, to examine the relationship between defecation function, perceived social support, and QoL in patients with rectal cancer.

\section{Study Participants}

The study participants were patients from a large tertiary referral hospital with 2,700 beds in Seoul, Korea, who had been diagnosed with rectal cancer and were on outpatient treatment after undergoing sphincter-saving resection. Using the $G^{*}$ power program, the significance lev$\mathrm{el}(\alpha)$ of .05 , power (1- $\beta)$ of .80, median effect size of .15 for regression analysis, and considering 13 independent variables (gender, age, marital status, living arrangement, education, employment status, monthly income, presence of caregiver, religion, surgical approach, time since surgery, social support and defecation dysfunction), the minimum required sample size was calculated to be 131 . A convenience sample of 140 patients was recruited, taking into consideration dropouts due to possible exhaustion or inconvenience during treatment. Nine patients were excluded because they were unable to answer the questionnaire sufficiently, or experienced cancer recurrence after treatment. The remaining 131 patients were included in the final analysis.

Participants were included in this study if 1 ) they were aged 20 years or older, diagnosed with rectal cancer, regardless of cancer stage, 2) they were between three months to five years since undergoing a low anterior resection, an ultralow anterior resection, or an inter-sphincteric resection and, 3) they continued to follow-up at the outpatient department or the colorectal clinic. These patients were particularly targeted because complications frequently occur within three months after sphincter-saving surgery, while survival after five years indicates that the patient is completely cured [17]. The following criteria 
were used to exclude participants from the study: 1) those who had temporary colostomy after low anterior resection for less than three months since stoma closure and, 2) those who were currently on chemotherapy owing to recurrence of cancer, did not undergo colostomy reversal after sphincter-saving surgery, or underwent a re-surgery to create an ostomy. All participants were able to communicate, read, and write, understand the purpose of the study, and provided consent to participate in the study.

\section{Instruments}

\section{1) Defecation function}

Defecation function was evaluated using the Memorial Sloan Kettering Cancer Center Bowel Function Instrument (MSKCC BFI) developed by Temple et al. [18], which is designed specifically for evaluating bowel function after sphincter-preserving surgery for rectal cancer. The Korean version of MSKCC BFI has been validated in patients with colorectal cancer [19] and was authorized for use in this study by the author. The MSKCC BFI consists of 18 questions and adopts a four-week recall period and equalweighting scoring. The indices of clinically meaningful characteristics of defecation, such as frequent defecation, dietary characteristics, and fecal urgency/incontinence, are scored using a five-point scale ranging from "always" (1) to "never" (5). Five items are reverse scored. The total score ranges from 18 to 90 , with higher scores indicating better defecation function. Cronbach's $\alpha$ values of the original tool [18], of the Korean version [19] were .87 and .78 , respectively, and as found in the current study was .81 .

\section{2) Social support}

Perceived social support was evaluated using the Multidimensional Scale of Perceived Social Support (MSPSS) developed by Zimet et al. [20]. The MSPSS has been translated into Korean and validated in a study of unemployed people [21].The Korean version was authorized for use in this study by the original author. The MSPSS contains 12 items that subjectively measure perceived social support using three subscales: family, friends, and significant others. In this study, items relating to support from "significant others" and a "special person" referred to the support from healthcare professionals such as a nurse.

In the original MSPSS, the 12 items are rated on a seven-point Likert-type scale. In this study, the 12 items were rated on a five-point Likert-type scale, with answers ranging from "strongly disagree" (1) to "strongly agree" (5). Higher scores indicate higher perceived social support. Cronbach's $\alpha$ values of the original study [20], the
Korean version [21], and in the current study were .85 , 0.89 , and 82 , respectively. Cronbach's $\alpha$ values of the subscales were .91 for family support, .91 for friends' support, and .92 for significant others' support.

\section{3) Quality of life}

QoL was evaluated using the Functional Assessment of Cancer Therapy-Colorectal (FACT-C) instrument developed by Ward et al. [22]. The FACT-C has been translated into Korean, and its reliability and validity have been tested [23]. Authorization from FACIT (www.facit.org) was received prior to the use of the FACT-C in this study. The instrument is divided into five domains: physical (7 items), social/family (7 items), emotional (6 items), functional (7 items), and colorectal cancer-specific (7 items). The 34 items are rated on a five-point scale ranging from "never" (0) to "always" (4). Negative items are reverse scored. Higher scores indicate higher perceived QoL. Cronbach's $\alpha$ values of the original tool [22], the tool validated in Korean [23], and as found in the current study were .87, .86 , and .92, respectively. Cronbach's $\alpha$ values of the FACT-C subscales were .83 for physical well-being, .88 for social/family well-being, .74 for emotional well-being, .92 for functional well-being, and .63 for colorectal cancer-specific items.

\section{Data Collection}

Data were collected from September to November 2014. All participants were receiving outpatient follow-up treatment at the colorectal cancer clinic after surgery for rectal cancer. The first author of this study, who consults patients as a coordinator at the colon cancer clinic, explained the purpose of the study to the participants and collected data through one-on-one interviews. Participants were asked to respond to a self-report questionnaire. If they had difficulty understanding the text, or if they had poor vision, the researcher read the questions aloud and recorded their responses. We provided a gift to all research participants for participating in the survey. Information about disease- and surgery-related characteristics were collected from electronic medical records.

\section{Ethical Consideration}

This study was approved by the institute ethics committee of the hospital (AMC \#2014-0951). Participants were informed of the purpose of the study, and possible risks and benefits related to their participation. Moreover, they were told that their participation was voluntary and that 
they had the right to withdraw from the study at any time. All participants were asked to sign a written consent form prior to participating in the survey.

\section{Data Analysis}

The collected data were analyzed using SPSS/WIN version 21.0 and AMOS version 21.0 (IBM Corp., Armonk, NY, USA). Descriptive statistics were used for the general characteristics of the participants, and means and standard deviations were used to describe defecation function (MSKCC BFI score), social support (MSPSS score), and QoL (FACT-C score). Student's t test and one-way Analysis of Variance (ANOVA) were used to examine the differences between the two groups according to the general characteristics of the participants. Scheffé's post hoc test was used to compare significance among multiple categories. Pearson's correlation coefficient was used to evaluate the correlations between the research variables, and multiple linear regression analysis was used to determine factors associated with QoL.

Path analysis was used to verify causal relationships between direct, indirect, and total effects of the three variables. Regression coefficient, standardized coefficient, standard error, critical ratio, and $p$ values were used to test the significance of paths in the structural equation model. Bootstrapping method $(1: 1,000)$ was used in examining the statistical significance of the model's direct, indirect, and total effects.

\section{RESULTS}

\section{Descriptive Statistics of Study Participants and Measured Variables}

Among the study participants, $61.8 \%$ were male and $87 \%$ were married. The mean age of the participants was $59.0 \pm 10.2$ years, and $68.7 \%$ had a high school diploma or college degree. As to the characteristics of their surgery, $46.6 \%$ had undergone robotic surgery, and $59.6 \%$ a lower anterior rectal resection. Additionally, 51.9\% had cancer in the stages II and III, $40.5 \%$ had a temporary stoma, and $56.5 \%$ underwent chemotherapy. Among the patients, $47.3 \%$ had undergone surgery in the previous 12 months, and the average time elapsed since surgery was $15.93 \pm$ 9.82 months (Table 1). The average scores for defecation function (MSKCC BFI), social support (MSPSS), and QoL (FACT-C) were $65.31 \pm 8.33,43.14 \pm 9.71$, and $98.80 \pm 19.62$, respectively.
Table 1. Demographic and Clinical Characteristics of Study Participants

$(N=131)$

\begin{tabular}{|c|c|c|}
\hline Characteristics & Categories & $\mathrm{n}(\%)$ or $\mathrm{M} \pm \mathrm{SD}$ \\
\hline \multirow[t]{2}{*}{ Gender } & Men & $81(61.8)$ \\
\hline & Women & $50(38.2)$ \\
\hline \multirow[t]{3}{*}{ Age (year) } & $30 \sim 59$ & $67(51.2)$ \\
\hline & $60 \sim 82$ & $64(48.8)$ \\
\hline & & $59.03 \pm 10.21$ \\
\hline \multirow{2}{*}{ Marital status } & Married & $114(87.0)$ \\
\hline & Single or widowed & $17(13.0)$ \\
\hline \multirow[t]{2}{*}{ Living with } & Family & $121(92.4)$ \\
\hline & Alone & $10(7.6)$ \\
\hline \multirow[t]{3}{*}{ Education } & $\leq$ Middle school & $41(31.3)$ \\
\hline & High school & $56(42.7)$ \\
\hline & $\geq$ College & $34(26.0)$ \\
\hline \multirow[t]{2}{*}{ Employment status } & Employed & $63(48.1)$ \\
\hline & Unemployed & 68 (51.9) \\
\hline \multirow{3}{*}{$\begin{array}{l}\text { Monthly income } \\
\text { (USD) }\end{array}$} & $<2,000$ & $54(41.2)$ \\
\hline & $2,000 \sim 4,000$ & $48(36.6)$ \\
\hline & $>4,000$ & $29(22.2)$ \\
\hline \multirow[t]{2}{*}{ Presence of caregiver } & Yes & $92(70.2)$ \\
\hline & No & $39(29.8)$ \\
\hline \multirow[t]{3}{*}{ Surgical approach } & Robotic & $61(46.6)$ \\
\hline & Laparoscopy & $17(13.0)$ \\
\hline & Open & $53(40.4)$ \\
\hline \multirow[t]{3}{*}{ Operative method } & LAR & $78(59.6)$ \\
\hline & uLAR & $40(30.5)$ \\
\hline & uLAR/ISR & $13(9.9)$ \\
\hline \multirow[t]{4}{*}{ Cancer stage } & 0 & $14(10.7)$ \\
\hline & $\mathrm{I}$ & $49(37.4)$ \\
\hline & II & $32(24.4)$ \\
\hline & III & $36(27.5)$ \\
\hline \multirow{3}{*}{$\begin{array}{l}\text { Anastomosis } \\
(\mathrm{cm} \text { from AV) }\end{array}$} & $\leq 5$ & $97(74.0)$ \\
\hline & $\geq 6$ & $34(26.0)$ \\
\hline & & $4.01 \pm 2.53$ \\
\hline \multirow[t]{2}{*}{ Temporary stoma } & Yes & $53(40.5)$ \\
\hline & No & $78(59.5)$ \\
\hline \multirow{2}{*}{$\begin{array}{l}\text { Experience of } \\
\text { radiotherapy }\end{array}$} & Yes & $43(32.8)$ \\
\hline & No & $88(67.2)$ \\
\hline \multirow{2}{*}{$\begin{array}{l}\text { Experience of } \\
\text { chemotherapy }\end{array}$} & Yes & $74(56.5)$ \\
\hline & No & $57(43.5)$ \\
\hline \multirow{4}{*}{$\begin{array}{l}\text { Time since surgery } \\
\text { (month) }\end{array}$} & $3 \sim 12$ & $62(47.3)$ \\
\hline & $13 \sim 24$ & $32(24.5)$ \\
\hline & $25 \sim 49$ & 37 (28.2) \\
\hline & & $15.93 \pm 9.82$ \\
\hline
\end{tabular}

$\mathrm{AV}=$ anal verge; $\mathrm{ISR}=$ intersphincteric resection; $\mathrm{LAR}=\mathrm{low}$ anterior resection; $\mathrm{uLAR}=\mathrm{ultralow}$ anterior resection. 


\section{Relationships between the Variables and Factors Affect- ing QoL}

Pearson correlation coefficients showed significant relationships between defecation function and social support $(\mathrm{r}=.20, p=.025)$, between defecation function and QoL $(\mathrm{r}=$ $.31, p=.001)$, and between social support and QoL ( $\mathrm{r}=.38$, $p=.001$ ). Bivariate analyses showed that QoL was significantly associated with education level ( $\mathrm{F}=3.51, p=.033)$ and employment status $(t=2.87, p=.005)$. High school graduates had a lower QoL than those with middle school or lower education, and those who graduated from college. Additionally, QoL was significantly higher in the employed group than in the unemployed group (Table 2).

In order to confirm the predictors of QoL among the patients, multiple linear regression analysis was conducted using forward selection. Among the independent variables, variance inflation factor $(1.02 \sim 1.05)$ and tolerance $(0.95 \sim 0.98)$ were within the normal range, satisfying the basic assumptions of multicollinearity $(p<.050)$. In addition to defecation function and social support, education level and employment status, which were statistically sig- nificant in the bivariate analysis, were included in the regression analysis. When adjusted for age and gender, the final regression model including defecation function, social support and employment status was statistically significant $(\mathrm{F}=7.14, p<.001)$ and accounted for the $25 \%$ of the variance (adjusted $\mathrm{R}^{2}=.25$ ) (Table 3 ).

\section{Path Analysis for the Mediating Effect of Social Support}

The path model was established based on previous studies and tested for the mediating effect of social support on the relationship between defecation function and QoL (Figure 1). The initial model was confirmed to be a saturated model with zero degrees of freedom and $x^{2}=0.00$, implying a perfect fit for the data, and therefore, it was not necessary to confirm the fitness index of the model. Standardized coefficients for the path model were all statistically significant $(p<.050)$. All three paths were statistically significant: defecation function affected social support $(\beta=.19$, $p=.031)$, social support affected QoL $(\beta=.33, p=.005)$, and defecation function affected $\mathrm{QoL}(\beta=.25, p=.021)$.

Defecation function had a positive direct effect on social

Table 2. Relationships between Participant Characteristics and Quality of Life

\begin{tabular}{|c|c|c|c|c|c|}
\hline Characteristics & Categories & $\mathrm{M} \pm S D$ & $\mathrm{t}$ or $\mathrm{F}$ & $p$ & Scheffé \\
\hline \multirow[t]{2}{*}{ Gender } & Men & $100.53 \pm 19.50$ & \multirow[t]{2}{*}{1.27} & \multirow[t]{2}{*}{.205} & \\
\hline & Women & $96.21 \pm 19.82$ & & & \\
\hline \multirow[t]{2}{*}{ Age (year) } & $<60$ & $101.73 \pm 19.41$ & \multirow[t]{2}{*}{1.85} & \multirow[t]{2}{*}{.066} & \\
\hline & $\geq 60$ & $95.44 \pm 19.50$ & & & \\
\hline \multirow[t]{2}{*}{ Marital status } & Married & $98.74 \pm 20.01$ & \multirow[t]{2}{*}{-0.12} & \multirow[t]{2}{*}{.901} & \\
\hline & Single or widowed & $99.32 \pm 8.13$ & & & \\
\hline \multirow[t]{2}{*}{ Living arrangements } & With family & $98.82 \pm 19.90$ & \multirow[t]{2}{*}{0.02} & \multirow[t]{2}{*}{.978} & \\
\hline & Alone & $99.00 \pm 17.02$ & & & \\
\hline \multirow[t]{3}{*}{ Education } & $\leq$ Middle school $^{\mathrm{a}}$ & $103.91 \pm 19.33$ & \multirow[t]{3}{*}{3.51} & \multirow[t]{3}{*}{.033} & \multirow[t]{3}{*}{$\mathrm{b}<\mathrm{a}, \mathrm{c}$} \\
\hline & High school $^{\mathrm{b}}$ & $93.82 \pm 18.13$ & & & \\
\hline & $\geq$ College $^{c}$ & $101.01 \pm 21.14$ & & & \\
\hline \multirow[t]{2}{*}{ Employment status } & Employed & $103.80 \pm 17.61$ & \multirow[t]{2}{*}{2.87} & \multirow[t]{2}{*}{.005} & \\
\hline & Unemployed & $94.23 \pm 20.42$ & & & \\
\hline \multirow[t]{2}{*}{ Religion } & Yes & $98.31 \pm 18.90$ & \multirow[t]{2}{*}{0.33} & \multirow[t]{2}{*}{.739} & \\
\hline & No & $99.52 \pm 20.81$ & & & \\
\hline \multirow[t]{3}{*}{ Monthly income (USD) } & $<2,000$ & $96.43 \pm 19.54$ & \multirow[t]{3}{*}{0.85} & \multirow[t]{3}{*}{.426} & \\
\hline & $2,000 \sim 4,000$ & $99.51 \pm 18.80$ & & & \\
\hline & $>4,000$ & $102.21 \pm 21.42$ & & & \\
\hline \multirow[t]{2}{*}{ Presence of caregiver } & Yes & $100.34 \pm 19.42$ & \multirow[t]{2}{*}{1.31} & \multirow[t]{2}{*}{.191} & \\
\hline & No & $95.40 \pm 20.10$ & & & \\
\hline \multirow[t]{3}{*}{ Time since surgery (month) } & $3 \sim 12$ & $100.52 \pm 19.21$ & \multirow[t]{3}{*}{0.56} & \multirow[t]{3}{*}{.570} & \\
\hline & $13 \sim 24$ & $96.00 \pm 22.43$ & & & \\
\hline & $25 \sim 49$ & 98.31士18.14 & & & \\
\hline
\end{tabular}


support ( $\beta=.38, p=.011)$, social support had a positive direct effect $(\beta=.49, p=.005)$ on $\mathrm{QoL}$, and defecation function had a positive direct effect $(\beta=.38, p=.021)$ and a positive indirect effect through social support $(\beta=.16, p=.007)$ on QoL (total effect $=0.47, p=.009$ ). The bootstrapping test for the indirect effect of social support on the relationship between defecation function and QoL showed a statistically significant relationship $(\beta=.06$, standard error $=.19, p=.005$, bias-corrected $95 \%$ confidence interval $=.02 \sim .06)$. Thus, social support mediated the relationship between defecation function and QoL (Table 4).

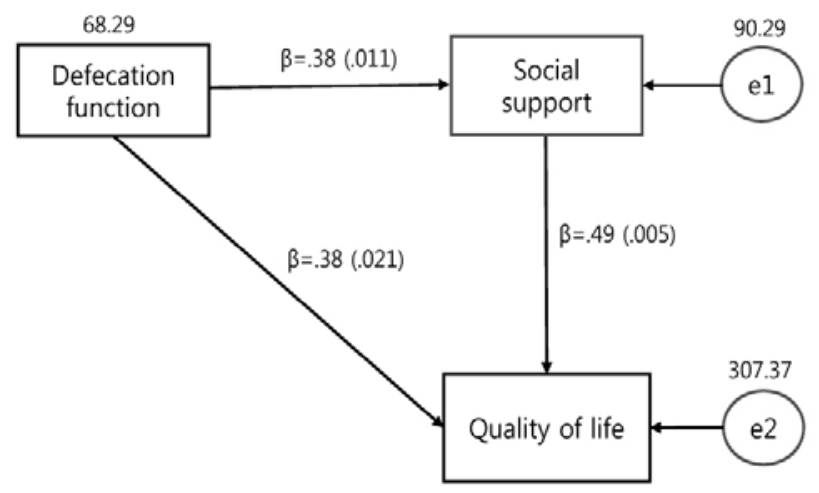

Figure 1. Path diagram of the model.

\section{DISCUSSION}

This study was conducted to identify the factors affecting QoL in patients with rectal cancer and to clarify the role of social support in relation to defecation function and QoL. Multiple regression analysis revealed that postoperative defecation function in rectal cancer patients significantly predicted QoL, which means that better defecation function was associated with higher QoL. This finding supports previous studies showing that rectal cancer patients with fecal incontinence and urgency after sphincter-saving resection surgery had significantly lower QoL than those without such problems [6,24]. In addition, this finding is consistent with the finding that defecation dysfunction is a major predictor of QoL following sphincter-preserving resection [25]. QoL of patients with rectal cancer was also closely associated with the severity of the low anterior resection syndrome [26] and cancer symptoms [27]. Changes in defecation function in rectal cancer patients was most pronounced during the first months after surgery, improved during the first year, and reached a steady state in one-two years after surgery [25]. However, since the time elapsed since surgery ranged from three to forty-nine months for participants in the study, additional longitudinal studies are needed to confirm the effects of

Table 3. Multiple Linear Regression Analysis for the Factors on Quality of Life

$(N=131)$

\begin{tabular}{|c|c|c|c|c|c|c|c|}
\hline Variables & & B & SE & $\beta$ & $\mathrm{t}$ & $p$ & $95 \% \mathrm{CI}$ \\
\hline (Constant) & & 27.43 & 18.43 & & 1.49 & .139 & \\
\hline Social support & & 0.63 & 0.16 & .32 & 3.04 & $<.001$ & $0.27 \sim 0.92$ \\
\hline Defecation function & & 0.56 & 0.19 & .25 & 3.04 & .003 & $0.13 \sim 0.87$ \\
\hline $\begin{array}{l}\text { Employment status } \\
\text { (ref.: unemployed) }\end{array}$ & Employed & 10.14 & 3.26 & .26 & 3.11 & .002 & $-18.60 \sim-3.56$ \\
\hline \multirow[t]{2}{*}{$\begin{array}{l}\text { Education } \\
\text { (ref.: } \leq \text { middle school) }\end{array}$} & $\begin{array}{l}\text { High school } \\
\geq \text { College }\end{array}$ & $\begin{array}{l}-9.19 \\
-7.66\end{array}$ & $\begin{array}{l}3.79 \\
4.34\end{array}$ & $\begin{array}{l}-.23 \\
-.17\end{array}$ & $\begin{array}{l}-1.93 \\
-1.76\end{array}$ & $\begin{array}{l}.057 \\
.080\end{array}$ & $\begin{array}{r}-9.20 \sim 0.23 \\
-11.89 \sim 0.79\end{array}$ \\
\hline & & \multicolumn{6}{|c|}{$\mathrm{R}^{2}=.29$, Adj. $\mathrm{R}^{2}=.25, \mathrm{~F}=7.14, p<.001$} \\
\hline
\end{tabular}

${ }^{\dagger}$ Adjusted for age and gender; $\mathrm{CI}=$ confidence interval; $\mathrm{SE}=$ standard error.

Table 4. Path Coefficients between Endogenous and Exogenous Variables in the Model

\begin{tabular}{|c|c|c|c|c|c|c|c|c|}
\hline $\begin{array}{l}\text { Endogenous } \\
\text { variables }\end{array}$ & $\begin{array}{c}\text { Exogenous } \\
\text { variables }\end{array}$ & B & $\beta$ & SE & $\mathrm{CR}(p)$ & $\begin{array}{c}\text { Standardized } \\
\text { direct effect }(p)\end{array}$ & $\begin{array}{c}\text { Standardized } \\
\text { indirect effect }(p)\end{array}$ & $\begin{array}{l}\text { Standardized } \\
\text { total effect }(p)\end{array}$ \\
\hline Social support & Defecation function & 0.23 & .19 & .10 & $2.27(.031)$ & $.38(.011)$ & & $.38(.011)$ \\
\hline Quality of life & Social support & 0.67 & .33 & .16 & $4.07(.005)$ & $.49(.005)$ & & $.49(.005)$ \\
\hline Quality of life & Defecation function & 0.58 & .25 & .19 & $3.05(.021)$ & $.38(.021)$ & $.16(.007)$ & $.47(.009)$ \\
\hline
\end{tabular}

$\mathrm{CR}=$ critical ratio; $\mathrm{SE}=$ standard error. 
postoperative duration on bowel function.

Some studies suggest that defecation function in rectal cancer patients can be restored in approximately $6 \sim 12$ months after surgery [28]. However, it typically cannot be restored to pre-surgical levels, and QoL is therefore impacted. A qualitative study found that rectal cancer patients who underwent sphincter saving resection did not receive care in relation to bowel problems over time, and did not know whom to consult [18]. This finding suggests that counseling and education are necessary for the patient even after discharge, and that nurses should follow-up on changes in defecation function of the patient for a considerable period of time after discharge.

In this study, social support was identified as a predictor of QoL. Path analysis also showed that there was a significant indirect effect of social support in the relationship between defecation function and QoL. This supports the findings of a previous study that colorectal cancer patients with more social support had better QoL at one year after surgery, when adjusted for age and gender, and that social support had a strong and positive direct effect on QoL [9]. In addition, this finding supports a nationwide study conducted in Korea showing that perceived social support played an important protective role in improving mental health and QoL in cancer patients [29]. Previous studies show that a strong perception of social support increase resilience and QoL, and decreased stress and anxiety in patients with colon cancer $[10,30]$. These findings highlight the need for healthcare providers to take steps to provide and strengthen timely social support in order help colorectal cancer survivors manage their defecation problems and improve their QoL [10].With regard to persistent, long-term bowel dysfunction in rectal cancer patients, we therefore suggest that experienced nurses, who are ideally placed to carry out advanced assessments, play an active role in supportive care [6] through counseling and providing information on future progress and healthmaintenance behavior.

Furthermore, social support was directly influenced by defecation function in the path analysis of this study. This finding is supported by a systematic review showing that colorectal cancer patients at a more advanced stage were more likely to be anxious and depressed, and have higher person-centered, supportive care needs than those at a less advanced stage [14]. Since perceived social support is an important factor influencing QoL, it is necessary to assess it regularly in patients with defecation problems during follow-up outpatient visits after surgery, and to provide targeted interventions to them. We encourage future studies to collect data from a more diverse sample of colorectal cancer patients and design a longitudinal study to examine the role of social support in alleviating the influence of defecation function on QoL.

We found that employment status was associated with QoL; in other words, QoL was better among those who were employed. This is consistent with a previous report that job type and employment status contributed to healthrelated QoL in cancer survivors [31]. This result is also similar to previous studies that defecation function affects employment status, which in turn influences QoL in rectal cancer patients $[6,32]$. These findings highlight the importance of employment status for QoL and further research is needed on returning to work after surgery for rectal cancer. Therefore, when patients with colorectal cancer requiring a long recovery period after surgery, and have a job, nurses and healthcare professionals should assess their return to work and job characteristics, and provide counseling to help them practice self-management at work.

The current study has some limitations. First, the study sample was obtained from a single medical center. Although numerous surgeries are performed in this hospital on a large number of rectal cancer patients, the study population cannot be considered to be representative of all rectal cancer survivors in Korea. Another limitation is the possible recall bias due to the use of a self-report questionnaire survey, and the fact that the data are not recent and were collected in 2014.

\section{CONCLUSION}

Perceived social support from family and healthcare professionals, defecation function, and employment status were found to be independent predictors of QoL in rectal cancer patients who underwent anal sphincter-saving surgery. Patients with better defecation function had higher perceived social support and higher QoL. In particular, social support partially mediated the relationship between defecation function and QoL. These results suggest that to improve the QoL of rectal cancer patients with defecation dysfunction, it is necessary to improve their perceived social support, and to periodically assess the degree of social support they perceive from family and healthcare providers. In order to do this, it is necessary to for outpatient clinics to provide periodic counseling and education for rectal cancer patients during the postoperative, follow-up period.

\section{CONFLICTS OF INTEREST}

The authors declared no conflict of interest. 


\section{AUTHORSHIP}

Study conception and design - KJR and HSY; Data collectionKJR; Analysis and interpretation of data - KJR and HSY; Drafting and critical revision of the manuscript - KJR and HSY.

\section{ACKNOWLEDGEMENT}

This article is a revision of the first author's master's thesis from Hanyang University.

\section{REFERENCES}

1. Jung K-W, Won Y-J, Oh C-M, Kong H-J, Lee DH, Lee KH. Cancer statistics in Korea: incidence, mortality, survival, and prevalence in 2014. Cancer Research Treatment. 2017;49(2): 292-305. https://doi.org/10.4143/crt.2017.118

2. Kim D-H. Colorectal cancer epidemic in Korea. Annals of Coloproctology. 2013;29(1):1-4. https://doi.org/10.3393/ac.2013.29.1.1

3. Kinoshita Y, Nokes KM, Kawamoto R, Kanaoka M, Miyazono M, Nakao H, et al. Health-related quality of life in patients with lower rectal cancer after sphincter-saving surgery: a prospective 6-month follow-up study. European Journal of Cancer Care. 2017;26(4):e12417. https://doi.org/10.1111/ecc.12417

4. Scheer AS, Boushey RP, Liang S, Doucette S, O'Connor AM, Moher D. The long-term gastrointestinal functional outcomes following curative anterior resection in adults with rectal cancer: a systematic review and meta-analysis. Diseases of the Colonand Rectum. 2011;54(12):1589-97. https://doi.org/10.1097/DCR.0b013e3182214f11

5. Bregendahl S, Emmertsen KJ, Lous J, Laurberg S. Bowel dysfunction after low anterior resection with and without neoadjuvant therapy for rectal cancer: a population-based crosssectional study. Colorectal Disease. 2013;15(9):1130-9. https://doi.org/10.1111/codi.12244

6. Knowles G, Haigh R, McLean C, Phillips HA, Dunlop MG, Din $\mathrm{FVN}$. Long term effect of surgery and radiotherapy for colorectal cancer on defecatory function and quality of life. European Journal of Oncology Nursing. 2013;17(5):570-7. https://doi.org/10.1016/j.ejon.2013.01.010

7. Deng M, Lan Y, Luo S. Quality of life estimate in stomach, colon, and rectal cancer patients in a hospital in China. Tumor Biology. 2013;34(5):2809-15. https://doi.org/10.1007/s13277-013-0839-3

8. Lee E, Kim KS. Relationships between anxiety, depression, low anterior resection syndrome, and quality of life following lower anterior resection for rectal cancer. Perspectives in Nursing Science. 2014;11(1):74-85. https://doi.org/10.16952/pns.2014.11.1.74

9. Kim HJ, Chu SH, Yoo JS, Kim NK. Nutritional risk and phys- ical activity on quality of life in patients with colorectal cancer. Asian Oncology Nursing.2014;14(2):66-73.

https://doi.org/10.5388/aon.2014.14.2.66

10. Costa ALS, Heitkemper MM, Alencar GP, Damiani LP, da Silva RM, Jarrett ME. Social support is a predictor of lower stress and higher quality of life and resilience in Brazilian patients with colorectal cancer. Cancer Nursing. 2017;40(5):5260. https://doi.org/10.1097/NCC.0000000000000388

11. Simon AE, Thompson MR, Flashman K, Wardle J. Disease stage and psychosocial outcomes in colorectal cancer. Colorectal Disease. 2009;11(1):19-25. https://doi.org/10.1111/j.1463-1318.2008.01501.x

12. Gonzalez-Saenz de Tejada M, Bilbao A, Baré M, Briones E, Sarasqueta C, Quintana JM, et al. Association of social support, functional status, and psychological variables with changes in health-related quality of life outcomes in patients with colorectal cancer. Psycho-Oncology. 2016;25(8):891-7. https://doi.org/10.1002/ pon.4022

13. Haviland J, Sodergren S, Calman L, Corner J, Din A, Fenlon D, et al. Social support following diagnosis and treatment for colorectal cancer and associations with health-related quality of life: results from the UK ColoREctal Wellbeing (CREW) cohort study. Psycho-Oncology. 2017;26(12):2276-84. https://doi.org/10.1002/pon.4556

14. Kotronoulas G, Papadopoulou C, Burns-Cunningham K, Simpson M, Maguire R. A systematic review of the supportive care needs of people living with and beyond cancer of the colon and/or rectum. European Journal of Oncology Nursing. 2017; 29:60-70. https://doi.org/10.1016/j.ejon.2017.05.004

15. van der Heijden JAG, Thomas G, Caers F, van Dijk WA, Slooter GD, Maaskant-Braat AJG. What you should know about the low anterior resection syndrome-clinical recommendations from a patient perspective. European Journal of Surgical Oncology. 2018;44(9):1331-7.

https://doi.org/10.1016/j.ejso.2018.05.010

16. Kim YS, Tae YS, Nam GH. Distress and quality of life among elderly patients with gastric cancer: the mediating effect of social support. Korean Journal of Adult Nursing. 2017;29(5): 536-46. https://doi.org/10.7475/kjan.2017.29.5.536.

17. Bennis M, Parc Y, Lefevre JH, Chafai N, Attal E, Tiret E. Morbidity risk factors after low anterior resection with total mesorectal excision and coloanal anastomosis: A retrospective series of 483 patients. Annals of Surgery. 2012;255(3):504-10. https://doi.org/10.1097/SLA.0b013e31824485c4

18. Temple LK, Bacik J, Savatta SG, Gottesman L, Paty PB, Weiser MR, et al. The development of a validated instrument to evaluate bowel function after sphincter-preserving surgery for rectal cancer. Diseases of the Colon and Rectum. 2005;48(7):135365. https://doi.org/10.1007/s10350-004-0942-z

19. Lim SM. The relationships among bowel function, health locus 
of control, anxiety and depression in patient with rectal cancer. [master's thesis]. Seoul: Ewha Womans University; 2013. p. 15.

20. Zimet GD, Dahlem NW, Zimet SG, Farley GK. The multidimensional scale of perceived social support. Journal of Personality Assessment. 1988;52(1):30-41.

https://doi.org/10.1207/s15327752jpa5201_2

21. Shin JS, Lee YB. The effects of social support on the psychosocial well-being of the unemployed. Korean Journal of Social Welfare. 1999;37:241-69.

22. Ward WL, Hahn EA, Mo F, Hernandez L, Tulsky DS, Cella D. Reliability and validity of the Functional Assessment of Cancer Therapy-Colorectal (FACT-C) quality of life instrument. Quality of Life Research. 1999;8(3):181-95. https://doi.org/10.1023/A:1008821826499

23. Kim H, Yoo H-J, Kim Y-J, Han O-S, Lee K-H, Lee J-H, et al. Development and validation of Korean Functional Assessment Cancer Therapy-General (FACT-G). Korean Journal of Clinical Psychology. 2003;22(1):215-29.

24. Mahalingam S, Seshadri RA, Veeraiah S. Long-term functional and oncological outcomes following intersphincteric resection for low rectal cancers. Indian Journal of Surgical Oncology. 2017;8(4):457-61. https://doi.org/10.1007/s13193-016-0571-8

25. Emmertsen KJ, Laurberg S. TheRectal Cancer Function Study Group. Impact of bowel dysfunction on quality of life after sphincter-preserving resection for rectal cancer. British Journal of Surgery Society. 2013;100(10):1377-87. https://doi.org/10.1002/bjs.9223

26. Juul T, Ahlberg M, Biondo S, Espin E, Jimenez LM, Matzel KE, et al. Low anterior resection syndrome and quality of life: an international multicenter study. Diseases of the Colon and
Rectum. 2014;57(5):585-91. https://doi.org/10.1097/DCR.0000000000000116

27. Oh PJ, Lim SY. Change of cancer symptom, depression and quality of life based on phases of chemotherapy in patients with colorectal or stomach cancer: a prospective study. Korean Journal of Adult Nursing. 2017;29(3):313-22. https://doi.org/10.7475/kjan.2017.29.3.313

28. Andersson J, Angenete E, Gellerstedt M, Angerås U, Jess P, Rosenberg J, et al. Health-related quality of life after laparoscopic and open surgery for rectal cancer in a randomized trial. British Journal of Surgery Society. 2013;100(7):941-9. https://doi.org/10.1002/bjs.9144

29. Eom C-S, Shin DW, Kim SY, Yang HK, Jo HS, Kweon SS, et al. Impact of perceived social support on the mental health and health-related quality of life in cancer patients: Results from a nationwide, multicenter survey in South Korea. Psycho-Oncology. 2013;22(6):1283-90. https://doi.org/10.1002/pon.3133

30. Kim JI, Byeon YS. A study on the factors affecting resilience in patients with colon cancer. Asian Oncology Nursing. 2013;13(4): 256-64. https://doi.org/10.5388/aon.2013.13.4.256

31. Duijts SFA, Kieffer JM, van Muijen P, van der Beek AJ. Sustained employability and health-related quality of life in cancer survivors up to four years after diagnosis. Acta Oncologica. 2017;56(2):174-82.

https://doi.org/10.1080/0284186X.2016.1266083

32. Kwoun HJ, Shin YH. Impact of bowel function, anxiety and depression on quality of life in patients with sphincter-preserving resection for rectal cancer. Journal of Korean Academy of Nursing. 2015;45(5):733-41. https://doi.org/10.4040/jkan.2015.45.5.733 